\title{
Distribution of Hatschekia pagellibogneravei (Copepoda: Hatschekiidae) on the gills of Pagellus bogaraveo (Teleostei: Sparidae) from Madeira, Portugal
}

\author{
Margarida Hermida $^{1,2}$, Cristina Cruz $^{1,2}$ and Aurélia Saraiva ${ }^{1,2}$ \\ ${ }^{1}$ Faculdade de Ciências, Universidade do Porto, Departamento de Biologia, Rua do Campo Alegre, Edifício FC4, $4169-007$ Porto, \\ Portugal; \\ ${ }^{2}$ CIIMAR, Interdisciplinary Centre of Marine and Environmental Research, University of Porto, Rua dos Bragas, 289, 4050-123 \\ Porto, Portugal
}

\begin{abstract}
A population of the gill parasite Hatschekia pagellibogneravei (Hesse, 1878) was studied on one of its sparid fish hosts, the blackspot seabream, Pagellus bogaraveo (Brünnich), off the coast of Madeira Island, Portugal, northeast Atlantic. Very high infection levels of this copepod were detected, with no significant seasonal differences. Abundance was negatively correlated with fish size. There were significant differences in the distribution of this copepod among the gill arches of the host, which seem to be best explained by differences in water flow within the gill habitat.
\end{abstract}

Keywords: copepoda, ectoparasites, marine fish, microhabitat, northeast Atlantic

The Hatschekiidae are a copepod family that comprises over 80 species, most of them tropical and subtropical (Kabata 1979). Despite the fact that these small copepods do not typically produce many eggs, they are remarkably successful, infecting numerous fish species, and sometimes aggregating in large numbers on their hosts (Jones 1998). They are characterized by a loss of definite segmentation in the region between the cephalothorax and the genital complex, which usually has a cylindrical shape. The males are much smaller than the females and they are unknown in numerous species (Kabata 1979, Jones 1985). Hatschekia pagellibogneravei (Hesse, 1878) (syn. $H$. pagellibogueravei) is a small and slender copepod that inhabits the gills of several fish of the family Sparidae (Raibaut et al. 1998, Boualleg et al. 2010a, 2011). It is easily distinguished from other members of the genus by its narrow, elongated form, and its characteristic posterodorsal conical protuberance on the cephalothorax (Scott 1909, Scott and Scott 1913, Kabata 1979, Jones 1985). The blackspot seabream, Pagellus bogaraveo (Brünnich, 1768) (syns. Sparus centrodontus, Pagellus centrodontus), has been reported as a host for this parasite both in the Atlantic Ocean (Scott 1909, Scott and Scott 1913) and in the Mediterranean Sea (Boualleg et al. 2010a).

The uneven distribution of gill parasites among the gill arches of the fish host is a well known phenomenon that can be related to both endogenous and environmental factors (Price 1980). A few studies have considered the distribution of Hatschekia spp. on the gills of their hosts. Martens and Moens (1995) and Geets et al. (1997) have studied the distribution of Hatschekia sp. on the gills of Siganus sutor (Valenciennes) off the Kenyan coast, and Lo and Morand (2001) analysed the distribution of Hatschekia sp. on the gills of a coral reef fish, Cephalopholis argus Schneider, from French Polynesia. Scott-Holland et al. (2006) have studied the distribution of the asymmetrical Hatschekia plectropomi Ho et Dojiri, 1978 on the gills of the coral trout, Plectropomus leopardus (Lacépède) from Australia. There is also a study on the distribution of Hatschekia hemigymni Kabata, 1991 on the gills of Hemigymnus melapterus (Bloch) from Australia (Muñoz and Cribb 2005). However, no studies have been carried out concerning $H$. pagellibogneravei on any of its hosts. During a survey conducted on the parasite communities of Pagellus bogaraveo from Portuguese waters, a very abundant population of the copepod $H$. pagellibogneravei was detected on fish collected in the region of Madeira (Hermida et al. 2012). Therefore, a study on the microhabitat distribution of this copepod on the gills of its host was performed. The influence of factors such as host size and seasonality was also evaluated.

\section{MATERIALS AND METHODS}

A total of 56 specimens of Pagellus bogaraveo captured off the coast of Madeira Island, Portugal, northeast Atlantic (36 in autumn and 20 in spring) were acquired from commercial 
catches. Fish were weighed and measured, and subsequently frozen in individual plastic bags. After defrosting, the gills were carefully removed and the left and right gill arches placed in separate Petri dishes. Each gill arch was individually observed under a stereomicroscope. All Hatschekia pagellibogneravei specimens were collected, counted and preserved in $70 \%$ ethanol $(\mathrm{v} / \mathrm{v})$. Whenever some copepods remained on the Petri dish after all the gill arches had been removed, they were included in the total amount of parasites on that gill, but no attempt was made to assign them to any particular gill arch. Other parasites detected were also collected, counted, preserved in $70 \%$ ethanol $(\mathrm{v} / \mathrm{v})$, and identified, but no statistical analysis was performed due to their low numbers.

Statistical analyses were carried out using IBM SPSS statistics software. Fish size (weight and fork length), intensity and abundance of infection were compared between seasons (autumn versus spring) using the non-parametric Mann-Whitney test. Fork length was preferred to total length for statistical analyses because damage to the caudal fin prevented accurate measurement of total length in some cases. The correlation between fish size (weight and fork length) and parasite abundance was analysed by Spearman rank correlation. The parasite abundance in the right and left sides was compared for the entire gill (RG/ LG) and for each gill arch (R1a/L1a; R2a/L2a; R3a/L3a; R4a/ L4a) using the non-parametric Wilcoxon signed ranks test. Parasite abundance was compared among the 4 arches for the left gill (L1a/L2a/L3a/L4a), right gill (R1a/R2a/R3a/R4a), and for both gills $(1 \mathrm{~A} / 2 \mathrm{~A} / 3 \mathrm{~A} / 4 \mathrm{~A})$, using the non-parametric Friedman's analysis of variance by ranks followed by multiple comparisons. For all tests, statistical significance was accepted when $\mathrm{p}<0.05$.

\section{RESULTS}

Of the 56 blackspot seabream observed, 54 were infected by the copepod Hatschekia pagellibogneravei, yielding an overall prevalence of $96 \%$. Mean intensity and abundance were also high (35.3 and 34.0, respectively). No male copepods were detected. The maximum intensity observed was 363 copepods on the gills of a single fish. Host parameters and infection levels are presented in Table 1. There were no significant differences between seasons for either fish weight (Mann-Whitney non-parametric test; $\mathrm{p}=0.078)$, fork length $(\mathrm{p}=0.245)$, or $H$. pagellibogneravei infection levels, namely, intensity $(\mathrm{p}=0.332)$ and abundance $(\mathrm{p}=0.436)$.
Table 1. Host (Pagellus bogaraveo) size and infection levels by Hatschekia pagellibogneravei (prevalence, intensity and abundance). No significant differences were observed between seasons of any of the parameters analysed (non-parametric MannWhitney test).

\begin{tabular}{lccc}
\hline & Total & Autumn & Spring \\
N (fish) & 56 & 36 & 20 \\
\hline Host weight (g): & & & \\
$\quad$ Mean \pm SD & $466 \pm 140$ & $426 \pm 75$ & $537 \pm 195$ \\
$\quad$ Median & 436 & 434 & 436 \\
$\quad$ Range) & $(310-983)$ & $(310-610)$ & $(347-983)$ \\
Host fork length $(\mathrm{cm}):$ & & & \\
$\quad$ Mean \pm SD & $27.8 \pm 2.2$ & $27.4 \pm 1.4$ & $28.6 \pm 3.0$ \\
Median & 27.3 & 27.4 & 27.3 \\
$\quad$ Range) & $(24.3-35.9)$ & $(24.3-30.1)$ & $(25.3-35.9)$ \\
Prevalence $(\%)$ & 96.4 & 97.2 & 95.0 \\
Intensity: & & & \\
Mean \pm SD & $35.3 \pm 63.2$ & $19.2 \pm 15.1$ & $64.8 \pm 99.6$ \\
Median & 17.5 & 16.0 & 19.0 \\
$\quad$ Range) & $(1-363)$ & $(1-54)$ & $(1-363)$ \\
Abundance: & & & \\
$\quad$ Mean \pm SD & $34.0 \pm 62.4$ & $18.7 \pm 15.2$ & $61.6 \pm 98.0$ \\
Median & 16.0 & 15.0 & 17.5 \\
$\quad$ Range) & $(0-363)$ & $(0-54)$ & $(0-363)$ \\
\hline
\end{tabular}

Abundance of $H$. pagellibogneravei was found to be significantly negatively correlated with fish size $(\mathrm{r}=-0.279, \mathrm{p}=0.037$ for weight and $\mathrm{r}=-0.281, \mathrm{p}=0.015$ for fork length). These correlations were also negative in spring $(\mathrm{r}=-0.518, \mathrm{p}=0.019$ for weight and $\mathrm{r}=-0.560$, $\mathrm{p}=0.010$ for fork length) and, although not statistically significant, in autumn $(\mathrm{r}=-0.190, \mathrm{p}=0.266$ for weight and $\mathrm{r}=-0.197, \mathrm{p}=0.249$ for fork length).

Abundance of $H$. pagellibogneravei on each particular arch and the significant differences detected are presented in Table 2. No significant differences in $H$. pagellibogneravei abundance were detected between the left and right gills either when analysed globally, or between corresponding gill arches. However, abundance of $\mathrm{H}$. pagellibogneravei varied significantly between different arches. Arch number 2 was the most parasitised, followed by arch 3 , then 1 , and lastly 4 . This pattern was observed on the left and right gills considered separately and also when both were combined. Gill arch number 4 was always significantly different from the second and third arches, and

Table 2. Distribution of Hatschekia pagellibogneravei on the gills of Pagellus bogaraveo. Statistically significant differences detected between gill arches on the left gill, right gill, and both gills combined by non-parametric Friedman's analysis of variance by ranks $\left(\mathrm{X}^{2}, \mathrm{p}\right.$ - probability level) followed by multiple comparisons (similar letters indicate no significant differences).

\begin{tabular}{|c|c|c|c|c|c|c|c|c|c|c|c|c|c|c|c|c|c|c|}
\hline \multirow[b]{2}{*}{ Abundance } & \multicolumn{6}{|c|}{ Left gill } & \multicolumn{6}{|c|}{ Right gill } & \multicolumn{6}{|c|}{ Both gills } \\
\hline & $1 \mathrm{~L}$ & $2 \mathrm{~L}$ & $3 \mathrm{~L}$ & $4 \mathrm{~L} \quad \mathrm{~L}$ & Unk.* & L Total L & $1 \mathrm{R}$ & $2 \mathrm{R}$ & $3 R$ & $4 \mathrm{R}$ & Unk.* & R Total R & $1 \mathrm{~L}+\mathrm{R}$ & $2 \mathrm{~L}+\mathrm{R}$ & $3 \mathrm{~L}+\mathrm{R}$ & $4 \mathrm{~L}+\mathrm{R}$ & Unk. $*$ L+R & Total L+R \\
\hline Mean & 3.9 & 5.0 & 3.9 & 1.91 & 1.9 & 16.6 & 3.5 & 5.0 & 4.4 & 2.2 & 2.3 & 17.4 & 7.3 & 10.1 & 8.3 & 4.1 & 4.2 & 34.0 \\
\hline SD & 6.5 & 10.5 & 8.3 & 4.32 & 2.5 & 29.7 & 8.4 & 8.7 & 9.6 & 4.9 & 3.5 & 33.0 & 14.5 & 19.0 & 17.5 & 8.9 & 5.0 & 62.4 \\
\hline Median & 1.0 & 1.5 & 1.0 & 0.01 & 1.0 & 7.0 & 1.0 & 2.0 & 1.5 & 1.0 & 1.0 & 8.5 & 2.0 & 4.5 & 3.0 & 1.0 & 2.0 & 16.0 \\
\hline Range & $0-35$ & $0-62$ & $0-45$ & $0-210$ & $0-10$ & $0-163$ & $0-46$ & $0-51$ & $0-58$ & $0-31$ & $0-16$ & $0-200$ & $0-79$ & $0-113$ & $0-97$ & $0-51$ & $0-23$ & $0-363$ \\
\hline $\begin{array}{l}\text { Significant } \\
\text { differences }\end{array}$ & \multicolumn{6}{|c|}{$\mathrm{X}^{2}=33.052 ; \mathrm{p}=0.000$} & \multicolumn{6}{|c|}{$X^{2}=27.437 ; p=0.000$} & \multicolumn{5}{|c|}{$\mathrm{X}^{2}=31.171 ; \mathrm{p}=0.000$} & \\
\hline
\end{tabular}

* Parasites that were found loose and could not be assigned to a specific gill arch. 
was also significantly different from the first both on the left gill and when data on both gills were combined.

The isopod Gnathia sp. was also detected on the gills of seven fish (prevalence of 13\%) and the diplectanid monogenean Lamellodiscus virgula Euzet et Oliver, 1967 on one fish (prevalence of $2 \%$ ), in both cases co-occurring with $H$. pagellibogneravei.

\section{DISCUSSION}

\section{Infection levels}

Infection levels in this study were higher than those previously reported, showing Hatschekia pagellibogneravei to be a common parasite of Pagellus bogaraveo off the coast of Madeira island. Although this parasite has been reported from blackspot seabream from the North Sea, it does not seem to be generally common in that region (Scott 1909). The highest prevalence reported for this parasite is $60 \%$, detected in Diplodus annularis (Linnaeus), and the highest mean abundance (6.83) was detected in P. bogaraveo off Algeria, Mediterranean Sea (Boualleg et al. 2010a, b).

Copepods of the genus Hatschekia Poche, 1902 are more common in tropical and subtropical waters (Kabata 1979). Hermida et al. (2012) did not detect a single specimen of $H$. pagellibogneravei in a sample of 206 blackspot seabream off mainland Portugal, and only detected a prevalence of $5.8 \%$ in the Azores. Rohde and Heap (1998) found an increased abundance of ectoparasites in lower latitudes, possibly due to differences in water temperature range. The island of Madeira is located in a subtropical region, which might help explain the high abundance of this copepod in this region. The highest intensity observed in this study, 363 individuals on a single host, is remarkably high. However, it is not uncommon for species of this genus because Romero and Kuroki (1986) reported an intensity of 948 specimens of Hatschekia affluens Castro-Romero et Baeza-Kuroki, 1986 on the gills of Pimelometopon maculatus (Jenyns) from Chile. Although most species of Hatschekia produce clutches of less than 10 eggs, the observed specimens of $H$. pagellibogneravei had egg-strings of up to 22 eggs each, which is unusual for such a small copepod, and indicates a high reproductive effort (Kabata 1981).

\section{Correlation between abundance and fish size}

A negative correlation was found between $H$. pagellibogneravei abundance and fish size (both length and weight). Most studies of Hatschekia spp. have either failed to detect any correlation with fish size (Collins 1984, Scott-Holland et al. 2006) or have detected positive correlations (Grutter 1994, Geets et al. 1997, Lo et al. 1998). A positive correlation of parasite abundance with fish size would be expected in the case of parasites that accumulate on the host over time, and Geets et al. (1997) suggested that this might be the case of Hatschekia spp. However, Jones (1998), reviewing the literature on copepod life spans, concluded that they live from 2 months to about a year. Although very little is known about the life cycle of Hatschekia spp. (Bergh et al. 2001), there is no reason to suppose them to be living longer than other copepod species, thus limiting their accumulation on the host over time.

A correlation between Hatschekia spp. abundance and fish size might instead be related to differences in habitat of fish from different age groups. This seems to be the case of Pagellus bogaraveo, which exhibits ontogenetic changes of habitat, the juveniles preferring shallow coastal waters whereas adults inhabit deeper waters of up to $700 \mathrm{~m}$ (Morato et al. 2001). Water temperature rapidly decreases with depth below the surface layer, and it is known to be a limiting factor for parasitic copepods (Jones 1998). The preference for shallow waters on the part of younger blackspot seabream might thus increase their probability of coming into contact with the infective stages of $H$. pagellibogneravei. However, more information on the ecology and life cycle of this copepod is needed in order to validate that hypothesis.

\section{Microhabitat distribution}

There were no significant differences in abundance between the left and right gill. Most studies on the distribution of Hatschekia spp. also failed to detect any difference in abundance between the left and right sides of the body (Martens and Moens 1995, Geets et al. 1997, Muñoz and Cribb 2005, Scott-Holland et al. 2006), nor would any such differences be expected to occur in symmetrical fish. Collins (1984) found significant differences in abundance of Hatschekia oblonga Wilson, 1913 between the left and right gill of the host, Ocyurus chrysurus (Bloch), but concluded that this was probably due to chance, which is likely, considering the low number of individuals involved.

There were significant differences in the distribution of $H$. pagellibogneravei among the four gill arches. The fourth arch was significantly less parasitised, and a II-IIII-IV pattern of infection was observed, although differences between the first three arches were not statistically significant. Two patterns of distribution of Hatschekia spp. on the gills of their hosts have so far been reported, namely a preference for the central gill arches in detriment of arches 1 and 4 (Lo and Morand 2001, Scott-Holland et al. 2006), and a preference for the first two arches with a decline towards the fourth arch (Collins 1984, Martens and Moens 1995, Geets et al. 1997, Muñoz and Cribb 2005). In almost all cases, arch number 4 is the least parasitised, a finding which is confirmed in this study. Differences in gill arch preference have been explained in terms of differential volumes of water passing through the four gill arches (Llewellyn 1956, Scott-Holland et al. 2006). Llewellyn (1956) suggested that these differences in wa- 
ter flow would be reflected in differences in opportunities of parasites to attach. The distribution of parasites on the gills might simply reflect the relative probability of contact with a particular gill arch. However, it could also be the case that parasites attached to gills suffering from stronger water currents might have greater difficulty in remaining attached, and hence have lower survival rates.

Paling (1968) studied the relative volumes of water flow passing through the four gill arches of trout, Salmo trutta Linnaeus, by using glochidia larvae as marker parasites. These entered the mouth passively with the respiratory current and then attached to the gill filaments, distributing themselves over the gills in proportions reflecting the volume of water passing through each gill (Paling 1968). This author observed that a much larger volume of water passed through the two middle gill arches, and that the fourth gill arch is the less ventilated. A II-III-I-IV pattern of infection was observed by Paling (1968), which is the exact same pattern as that observed for $H$. pagellibogneravei in the present study. In fact, disregarding those parasites of uncertain provenance, the percentages of $H$. pagellibogneravei detected in each gill arch pair $(24.6 \%, 33.7 \%, 28.0 \%, 13.7 \%)$ very closely resemble the proportions of glochidia larvae on the gills of trout $(25.1 \%$, $32.5 \%, 27.5 \%$, and $14.9 \%$, respectively) found by Paling (1968), suggesting that the distribution of H. pagellibogneravei is conditioned by differences in water flow within the gill habitat.

Other explanations that have been proposed to account for differences in microhabitat preferences of gill parasites include the effect of predators (Scott-Holland et al. 2006), interspecific competition and aggregation for increased mating opportunities (Rohde 1991). The effect of predators on Hatschekia spp. populations is poorly known; however, Scott-Holland et al. (2006) found that
H. plectropomi did not seem to be particularly targeted by cleaner fish, suggesting that these fish probably select larger parasite species, overlooking these very small and relatively inconspicuous copepods. With regard to interspecific competition, there was relatively little contact of $H$. pagellibogneravei with other gill parasites of $P$. bogaraveo in the present study, so it was not possible to evaluate the effect, if any, of interspecific competition on microhabitat preferences. Timi (2003) evaluated the hypothesis of aggregation to facilitate mating in Lernanthropus cynoscicola Timi et Etchegoin, 1996 and rejected it, having found that aggregation among individuals of the same sex was stronger than among males and females. All H. pagellibogneravei specimens detected in the present study were female and, in fact, the male of this species is currently unknown; therefore, the data do not allow any speculation regarding the hypothesis of aggregation to facilitate mating.

Differences in water flow seem, in this case, to constitute the best explanation for the distribution pattern observed. It remains, however, unclear whether this distribution pattern results simply from differences in the probability of attachment, as suggested by Llewellyn (1956), or by an active preference of the copepod for better ventilated gills, for example due to specific respiratory requirements (Timi 2003). The fact that specimens of Hatschekia spp. seem to have the capacity to move on the gill habitat (Lo and Morand 2001) suggests that the distribution of these copepods on the gills of the host could indeed involve an active preference.

Acknowledgements. This work was financially supported by Fundação para a Ciência e Tecnologia (M. H., Grant SFRH/ BD/47767/2008). The authors wish to thank João Delgado and Fernando Alexandre for their help in obtaining the fish samples.

\section{REFERENCES}

Bergh O., Nilsen F., Samuelsen O.B. 2001: Diseases, prophylaxis and treatment of the Atlantic halibut Hippoglossus hippoglossus: a review. Dis. Aquat. Org. 48: 57-74.

Boualleg C., Ferhati H., Kaduachi N., Bensouilah M., Ternengo S. 2010b: The copepod parasite of the gills of four teleost fishes caught from the gulf of Annaba (Algeria). Afr. J. Microbiol. Res. 4: 801-807.

Boualleg C., Kaouachi N., Seridi M., Ternengo S., BensouiLAH M.A. 2011: Copepod parasites of gills of 14 teleost fish species caught in the gulf of Annaba (Algeria). Afr. J. Microbiol. Res. 5: 4253-4259.

Boualleg C., Seridi M., Kaouachi N., Quiliquini Y., BensouILlAH M. 2010a: Les Copépodes parasites de poissons téléostéens du littoral Est-Algérien. Bull. Inst. Sci., Rabat, Section Sciences de la Vie 32: 65-72.

Collins M.R. 1984: Hatschekia oblonga (Copepoda, Caligoida) from yellowtail snapper (Ocyurus chrysurus) in the Florida Keys. J. Wildlife Dis. 20: 63-64.
Geets A., Coene H., Ollevier F. 1997: Ectoparasites of the whitespotted rabbitfish, Siganus sutor (Valenciennes, 1835) off the Kenyan Coast: distribution within the host population and site selection on the gills. Parasitology 115: 69-79.

Grutter A.S. 1994: Spatial and temporal variations of the ectoparasites of seven reef fish species from Lizard Island and Heron Island, Australia. Mar. Ecol. Prog. Ser. 115: 21-30.

Hermida M., Cruz C., Saraiva A. 2012: Ectoparasites of the blackspot seabream Pagellus bogaraveo (Teleostei: Sparidae) from Portuguese waters of the NE Atlantic. J. Mar. Biol. Ass. UK. (In press.) DOI: 10.1017/S0025315412000057

Jones J.B. 1985: A revision of Hatschekia Poche, 1902 (Copepoda: Hatschekiidae), parasitic on marine fishes. New Zeal. J. Zool. 12: $213-271$.

Jones J.B. 1998: Distant water sailors: parasitic Copepoda of the open ocean. J. Marine Syst. 15: 207-214.

Kabata Z. 1979: Parasitic Copepoda of British Fishes. The Ray Society, London, UK, 468 pp. 
Kabata Z. 1981: Copepoda (Crustacea) parasitic on fishes: problems and perspectives. Adv. Parasitol. 19: 1-71.

LLEWELLYN J. 1956: The host-specificity, micro-ecology, adhesive attitudes, and comparative morphology of some trematode gill parasites. J. Mar. Biol. Assoc. UK 35: 113-127.

Lo C.M., Morand S. 2001: Gill parasites of Cephalopholis argus (Teleostei: Serranidae) from Moorea (French Polynesia): site selection and coexistence. Folia Parasitol. 48: 30-36.

Lo C.M., Morand S., Galzin R. 1998: Parasite diversity/host age and size relationship in three coral-reef fishes from French Polynesia. Int. J. Parasitol. 28: 1695-1708.

Martens E., Moens J. 1995: The metazoan ecto- and endoparasites of the rabbitfish Siganus sutor (Cuvier \& Valenciennes, 1835) of the Kenyan coast. I. Afr. J. Ecol. 33: 405-416.

Morato T., Solà E., Grós M.P., Menezes G. 2001: Feeding habits of two congener species of seabreams, Pagellus bogaraveo and Pagellus acarne, off the Azores (Northeastern Atlantic) during spring of 1996 and 1997. Bull. Mar. Sci. 69: 1073-1087.

MuÑoz G., CRiBB T.H. 2005: Infracommunity structure of parasites of Hemigymnus elapterus (Pisces: Labridae) from Lizard Island, Australia: the importance of habitat and parasite body size. J. Parasitol. 91: 38-44.

Paling J.E. 1968: A method of estimating the relative volumes of water flowing over the different gills of a freshwater fish. J. Exp. Biol. 48: 533-544.

Price P. W. 1980. Evolutionary Biology of Parasites. Princeton University Press, Princeton, New Jersey, USA, 256 pp.

Received 23 January 2012
Raibaut A., Combes C., Benoit F. 1998: Analysis of the parasitic copepod species richness among Mediterranean fish. J. Marine Syst. 15: 185-206.

RoHDE K. 1991: Intra- and interspecific interactions in low density populations in resource-rich habitats. Oikos 60: 91-104.

Rohde K., Heap M. 1998: Latitudinal differences in species and community richness and in community structure of metazoan endo- and ectoparasites of marine teleost fish. Int. J. Parasitol. 28: 461-474.

Romero R.C., Kuroki H.B. 1986: Two new species of Hatschekia Poche 1902 (Copepoda, Hatschekiidae) parasitic on two inshore fishes from Antofagasta, Chile. J. Nat Hist. 20: 439-444.

Scotт T. 1909: Some Notes on Fish Parasites. Twenty-sixth annual report of the Fishery Board for Scotland, Being for the Year 1907. Part III - Scientific Investigations, James Hedderwick and Sons Ltd, Glasgow, Scotland, UK, pp. 73-92.

Scotт T., Sсотт A. 1913: The British Parasitic Copepoda. Vol. 1. Copepoda Parasitic on Fishes. The Ray Society, London, UK, $252 \mathrm{pp}$.

Scott-Holland T.B., Bennett S.M., Bennett M.B. 2006: Distribution of an asymmetrical copepod, Hatschekia plectropomi, on the gills of Plectropomus leopardus. J. Fish Biol. 68: 222-235.

Tiмi J. T. 2003: Habitat selection by Lernanthropus cynoscicola (Copepoda: Lernanthropidae): host as physical environment, a major determinant of niche restriction. Parasitology 127: 155-163.

Accepted 27 March 2012 